Institute of $\mathbf{F}_{\text {ood and }} \mathbf{A}$ gricultural $\mathbf{S}_{\text {ciences }}$

\title{
Preparing Healthful Ethnic Foods ${ }^{1}$
}

\author{
R. Elaine Turner and Linda B. Bobroff ${ }^{2}$
}

\section{Introduction}

Eating a variety of foods is the best way to get all the nutrients you need to look and feel your best. One tasty way to increase variety in your food choices is to include ethnic foods like Chinese, Mexican, Italian, Greek, and others. But how do you know that you are making healthful choices?

\section{Making Ethnic Choices}

Whether you're eating out, or cooking at home, keep the Food Guide Pyramid in mind for balancing your diet. The Pyramid emphasizes plant foods, and includes only moderate amounts of dairy products and meat/meat alternates.

Grains are the foundation of a healthful diet, and ethnic choices such as rice and pasta are familiar to most Americans. But have you tried Indian basmatti rice or Asian noodles? Pita bread or bagels can be sandwich alternatives, and barley or bulgur can be used for a tasty "starch" side dish. For fiber choose whole grains more often.

Many cultures use fruits and vegetables liberally. Try an unfamiliar fruit, maybe a tropical variety like star fruit, guava, or papaya. What about a stir-fry with Chinese cabbage, snow peas, and water chestnuts? Add a small amount of chicken or beef, or use tofu instead, for protein needed for growth and development.

\section{Finding and Trying New Recipes}

When you're ready to expand your horizons, spend time in the cookbook section of your local library. Choose one from each of several cuisines, and start looking through them. Try something that sounds good, and also looks simple to prepare. When you start reading the ingredients, you may find that many of them are already in your kitchen. Many ethnic cooking styles use similar ingredients, but with different mixes of herbs and spices.

Some styles of cooking can be made more healthful by making a few simple changes. Try frying in a non-stick pan or wok with only a small amount of oil. Cut salt seasonings in half, or eliminate them altogether if other flavors are present. Many recipes with added butter, margarine or oil can be made with less fat without losing any flavor. Mixed dishes can be just as

1. This document is FCS8757, one of a series of the Department of Family, Youth and Community Sciences, Florida Cooperative Extension Service, Institute of Food and Agricultural Sciences, University of Florida. First published: January 2000. Reviewed: August 2002. Please visit the EDIS Web site at http://edis.ifas.ufl.edu

2. R. Elaine Turner, PhD, RD, associate professor, Food Science and Human Nutrition Department and Linda B. Bobroff, PhD, RD, LD/N, associate professor, Department of Family, Youth and Community Sciences, Institute of Food and Agricultural Sciences, University of Florida, Gainesville, FL 32611. Reviewed by Shirley R. Bond, MS and Mary E. Chernesky, MS, Hillsborough County Extension Service; Nancy Gal, MS, Marion County Extension Service; Gerald R. Culen, PhD, Marie S. Hammer, MS, and Isabel Valentín-Oquendo, MS, RD, LD/N, Department of Family, Youth and Community Sciences, Institute of Food and Agricultural Sciences, University of Florida, Gainesville, FL 32611.

The Institute of Food and Agricultural Sciences is an equal opportunity/affirmative action employer authorized to provide research, educational information and other services only to individuals and institutions that function without regard to race, color, sex, age, handicap, or national origin. For information on obtaining other extension publications, contact your county Cooperative Extension Service office. Florida Cooperative Extension Service / Institute of Food and Agricultural Sciences / University of Florida / Christine Taylor Waddill, Dean 
tasty with less meat and more vegetables, a change that lowers fat, and increases fiber and nutrients.

\section{Recipes to Try}

Appetizers are always a good way to try new foods. Maybe a new dip or spread would liven up your next get-together.

\section{Hummus with Pita Bread}

1 can chick peas (garbanzo beans), drained and rinsed

$1 / 4$ cup sesame tahini

3 Tbsp lemon juice

3 cloves garlic, minced

$1 / 2$ tsp paprika

dash cayenne pepper

$1 / 4$ tsp cumin (optional)

$1 / 2$ tsp coriander powder (optional)

water as needed

1 package whole-wheat pita bread

\section{Directions:}

1. In a food processor, combine all ingredients except pita bread and process until smooth. Add water as needed. Hummus should be thick, not pourable.

2. Cut each individual pita bread into 8 triangles and serve with hummus.

\section{Guacamole}

2 avocados, medium-sized, peeled and chopped (not mashed)

1 tomato, medium-sized, chopped

$1 / 3$ cup onion, chopped

1 Tbsp lemon or lime juice (fresh is best)

1 Tbsp salsa

2 Tbsp fresh cilantro leaves, chopped

1 clove garlic, minced

\section{Directions:}

Combine all the ingredients in a bowl and mix them well using a wooden spoon or ceramic utensil (metal tends to turn avocados black).

Serve with baked tortilla chips.

\section{For More Information}

If you're Internet-savvy, check out the following sites:

http://www.eatethnic.com

Four Winds Food Specialists

This site answers your cultural questions, offers a bookstore full of references and cookbooks. It even has recipes, a newsletter, and health data on different cultures.

http://www.fcs.uga.edu/ selbon/apple/guides

Sound Nutrition-An International Appeal The information in this site was compiled for the 1996 Olympic Games in Atlanta. Specific dietary guidelines are given for countries around the world.

\section{http://www.usda.gov/cnpp/insight2.pdf}

This is one of a series of Nutrition Insights-short newsletters from the USDA Center for Nutrition Policy and Promotion. This issue compares the USDA Food Guide Pyramid to food guide pyramids representing Mediterranean, Asian, and Latin American cultures.

\section{Other References}

Kittler PG, Sucher KP. 1998. Food and Culture in America: A Nutrition Handbook. $2^{\text {nd }}$ ed. Belmont, CA: Wadsworth Publ. Co.

Lieberman LS and Bobroff LB. 1995. Cultural Food Patterns in Florida, $3^{\text {rd }}$ edition, UF/ IFAS, Florida Cooperative Extension Service, 